\title{
Launching of the CAN-R Web site - The official Web site of the Canadian Antimicrobial Resistance Alliance
}

\author{
George G Zhanel PhD ${ }^{1}$, Donald E Low MD²
}

\section{I}

Tnfectious diseases caused by antimicrobial- and antifungalresistant pathogens are causing a global crisis. Common antimicrobial-resistant pathogens include methicillin-resistant Staphylococcus aureus (both community-associated and health care-associated), vancomycin-resistant Enterococcus faecium, penicillin-resistant Streptococcus pneumoniae, Clostridium difficile, extended-spectrum beta-lactamase-producing enterobacteriaceae, multidrug-resistant Gram-negative bacilli, multidrugresistant Mycobacterium tuberculosis, and azole-resistant fungi.

Canadian clinicians and scientists require a dynamic, turnkey resource that will help address the growing problem of antimicrobial- and antifungal-resistant infectious diseases. Access to provincial, regional and national data on antimicrobial resistance in various infections and pathogens, as well as data on antimicrobial and antifungal usage, is necessary to combat the evolution of resistance in Canada.

The mission of the CAN-R Web site <www.canr.info> (Figure 1) is to create a unique, multipurpose, multidisciplinary, content-based infectious diseases and medical microbiology Web site that will address Canadian challenges and issues in antimicrobial and antifungal resistance and usage. As Co-Editors of CAN-R, our goal along with the Editorial Board (see Appendix) is to make this Web site a major entity in infectious diseases and medical microbiology in Canada over the next five to 10 years. The Web site will be used by a vast audience of Canadian clinicians who are interested in surveillance of resistant pathogens, antimicrobial and antifungal susceptibility trends, antimicrobial and antifungal utilization, new antimicrobials, and educational content, including infectious diseases treatment guidelines and mechanisms of antimicrobial action and resistance. The Co-Editors and the Editorial Board will continuously update and augment the Web site with the most current data, new studies, animations of antimicrobial action and resistance, and information on new antimicrobials. Web site users will find these resource 'tools' highly conducive to both learning and teaching. An important aspect of this Web site will be the availability of extensive downloads, including PowerPoint presentations on antimicrobial and antifungal resistance and usage, and infectious diseases treatment guidelines.

The major target audience of this site will be infectious diseases specialists (teaching and non-teaching), medical microbiologists, clinical and basic microbiologists, clinical pharmacists and nurses. In addition, researchers, respirologists, intensivists, urologists, hospital clinicians and surgeons will also be important audiences who will greatly benefit from this Web site. The CAN-R Web site will be a multisponsored, multiendorsed initiative with support from the Association of Medical Microbiology and Infectious Disease Canada and the Public Health Agency of Canada. The CAN-R Web site will actively seek partnerships and collaborations with existing Canadian and international organizations concerned about antimicrobial-resistant infections. We look forward to working hard along with our Editorial Board to provide Canadian physicians and scientists the latest information regarding antimicrobial and antifungal resistance and usage issues.

${ }^{1}$ Department of Medical Microbiology, Faculty of Medicine, University of Manitoba, and Departments of Medicine and Clinical Microbiology,

Health Sciences Centre, Winnipeg, Manitoba; ${ }^{2}$ Department of Laboratory Medicine and Pathobiology, Department of Medicine, University of

Toronto and University Health Network/Mount Sinai Hospital, Toronto, Ontario

Correspondence: Dr George G Zhanel, Department of Clinical Microbiology, Health Sciences Centre, MS673-820 Sherbrook Street, Winnipeg,

Manitoba R3A 1R9. Telephone 204-787-4902, fax 204-787-4699, e-mail ggzhanel@pcs.mb.ca

Received and accepted for publication January 25, 2007 


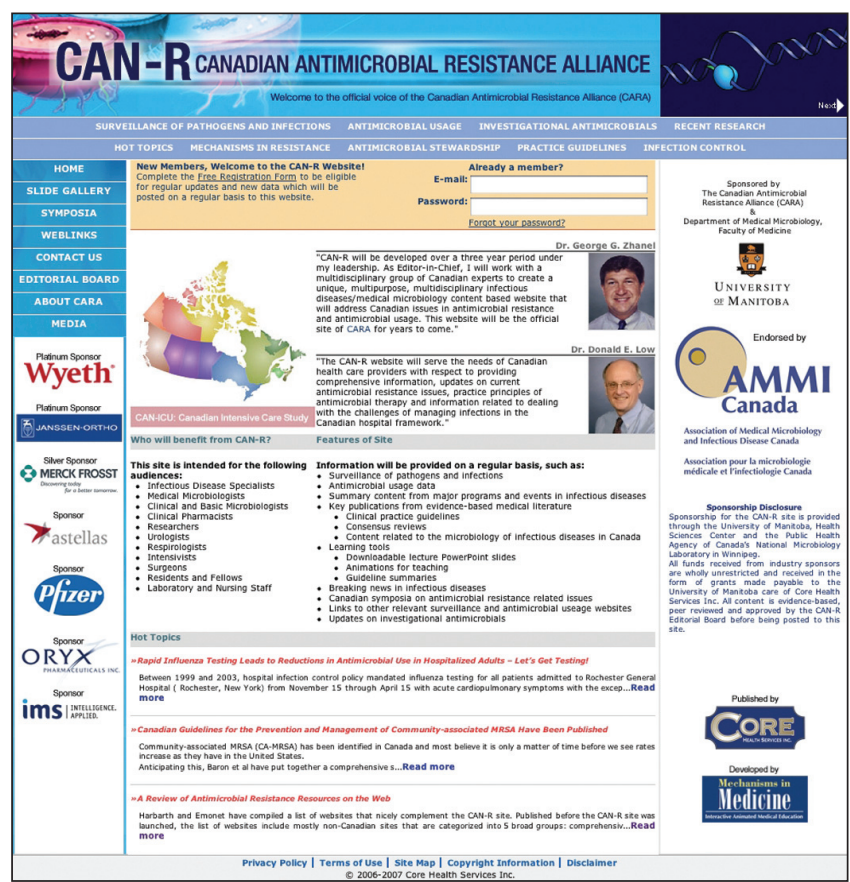

Figure 1) Screenshot of the CAN-R Web site <www.canr.info>

\section{Editorial Board}

\section{APPENDIX}

George G Zhanel PhD FCCP (co-Editor-in-Chief), Professor, Medical Microbiology, University of Manitoba Faculty of Medicine, Coordinator, Antibiotic Resistance Program, Health Sciences Centre, Winnipeg, Manitoba;

Donald E Low MD FRCPC (co-Editor), Professor, Department of Laboratory Medicine and Pathobiology, Department of Medicine, University of Toronto, Microbiologist-in-Chief, University Health Network/Mount Sinai Hospital, Toronto, Ontario;
Coleman Rotstein MD FRCPC FACP, Professor of Medicine, Division of Infectious Diseases, McMaster University, Henderson Site, Hamilton Health Sciences, Hamilton, Ontario;

Alfred Gin BSc Pharm PharmD, Assistant Professor, Department of Medical Microbiology, Faculty of Medicine, University of Manitoba; Clinical Pharmacist - Infectious Diseases, Health Sciences Centre, Winnipeg, Manitoba;

Gerald Evans MD FRCPC, Associate Professor of Medicine, Queen's University, Division of Infectious Diseases, Kingston General Hospital, Kingston, Ontario;

Tony Mazzulli MD FRCPC, Associate Professor, University of Toronto, Deputy Chief Microbiologist, Mount Sinai Hospital, Toronto, Ontario;

Susan M Poutanen MD MPH FRCPC, Assistant Professor, Departments of Laboratory Medicine and Pathobiology and Medicine, Microbiologist and Infectious Disease, Consultant, Toronto Medical Laboratories and Mount Sinai Hospital; Deputy Chief Microbiologist, Mount Sinai Hospital, Toronto, Ontario;

Michael Mulvey PhD ARMCCM, Chief, Antimicrobial Resistance and Nosocomial Infections, National Microbiology Laboratory, Winnipeg, Manitoba;

Daryl J Hoban PhD FCCM D(ABMM) F(AAM), Professor, University of Manitoba, Microbiologist, Health Sciences Centre, Winnipeg, Manitoba;

Grant Stiver MD FRCPC, Professor of Medicine, Division of Infectious Diseases, Department of Medicine, University of British Columbia, and Vancouver General Hospital, Vancouver, British Columbia;

Michel Laverdière MD, Professor, University of Montreal, Director, Laboratory Program, Hôpital MaisonneuveRosemont, Montreal, Quebec. 


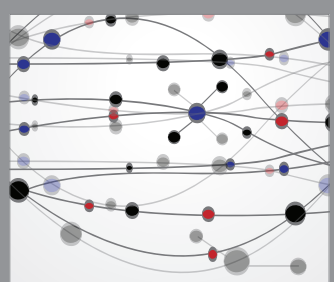

The Scientific World Journal
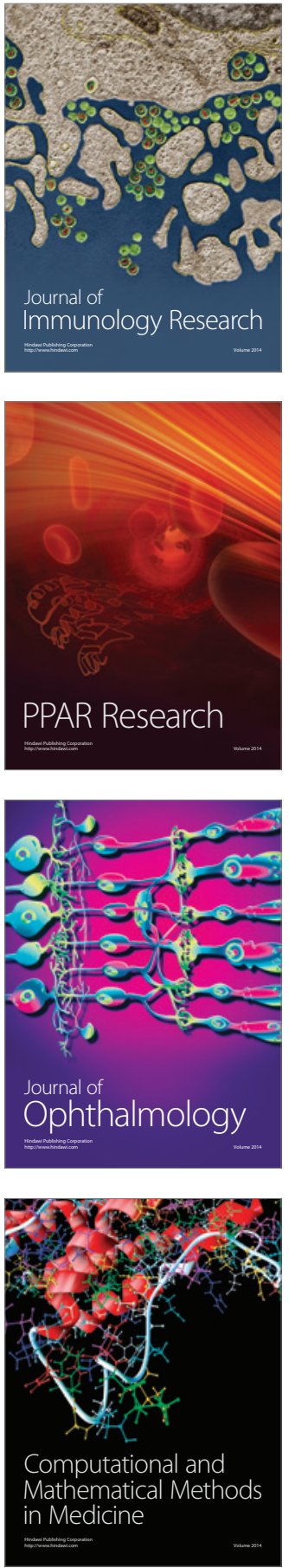

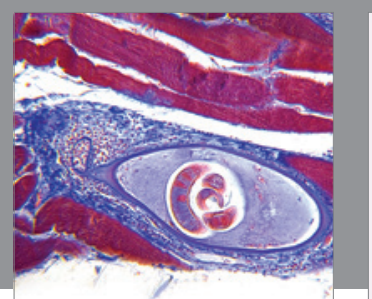

Gastroenterology Research and Practice

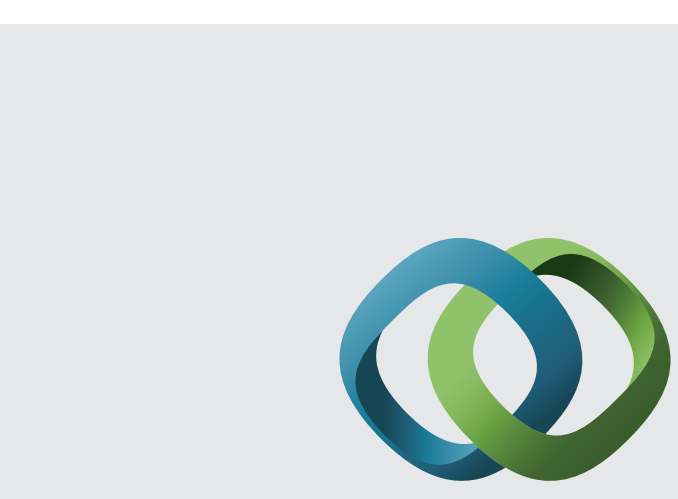

\section{Hindawi}

Submit your manuscripts at

http://www.hindawi.com
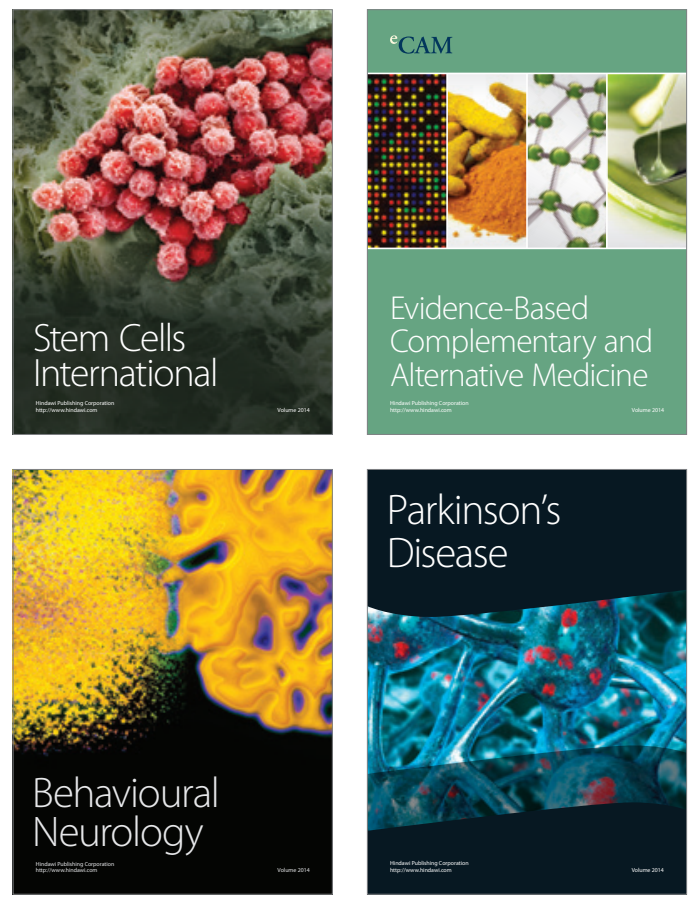
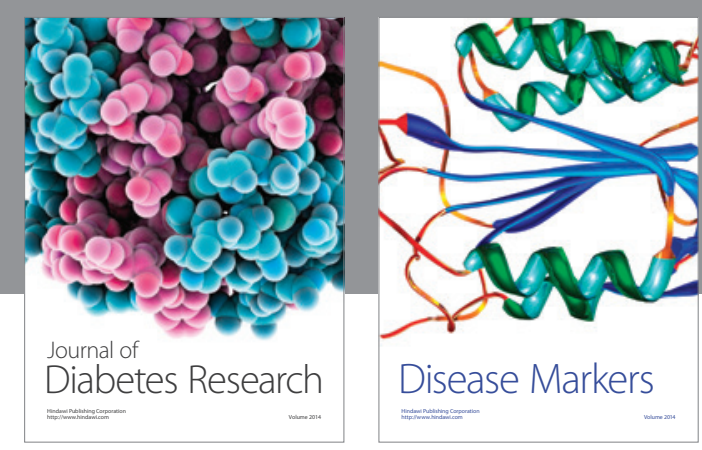

Disease Markers
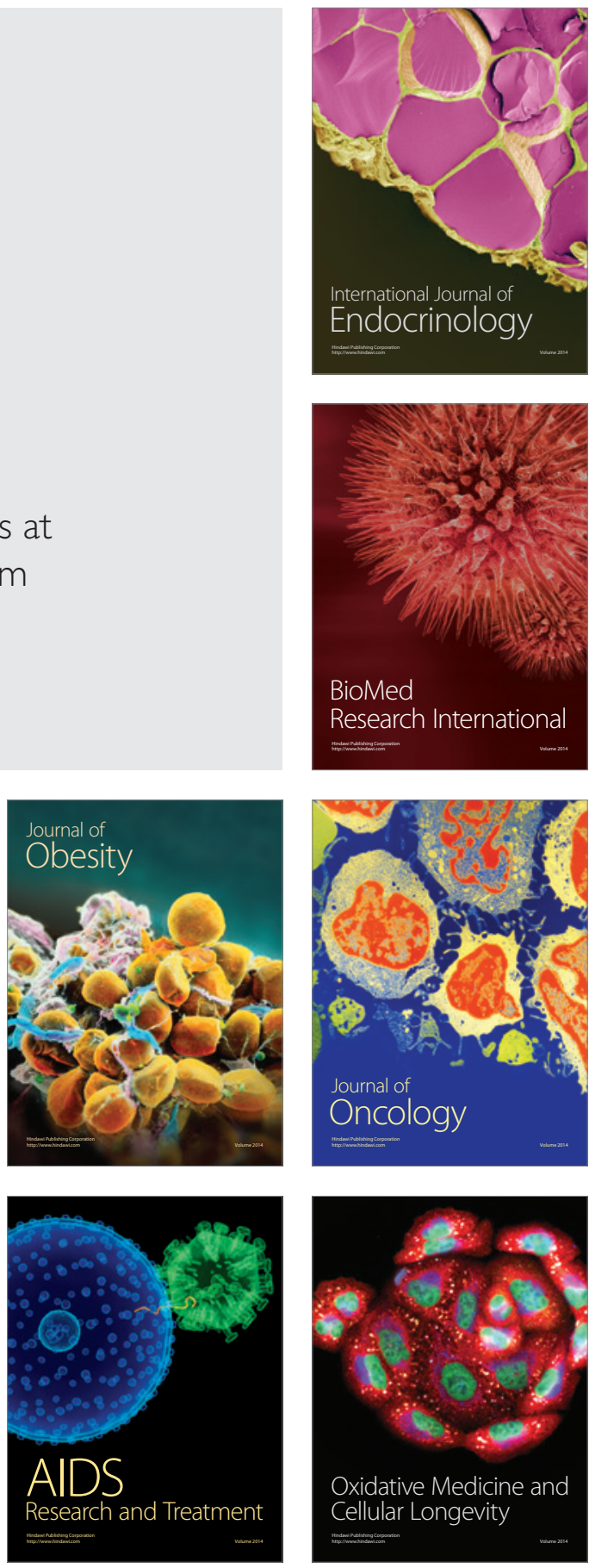